\title{
Design of stream barbs for field scale application at Sawmill Creek, Ottawa
}

\author{
E. C. Jamieson, C. D. Rennie \& R. D. Townsend \\ Department of Civil Engineering, University of Ottawa, Canada
}

\begin{abstract}
A three-dimensional numerical model Simulation in Intakes with Multiblock option (SSIIM) was used to model the effects of placing a series of barbs along an unstable section of Sawmill Creek, a small urban stream in the city of Ottawa, Canada. Stream barbs (a type of submerged groyne) are low-profile linear rock structures that prevent the erosion of stream banks by redirecting high velocity flow away from the bank. As they can be built at a relatively low cost and also provide significant ecological benefit, these structures are an important and relatively new method of stream bank protection. The numerical model was used to assess various design alternatives for a series of seven stream barbs at two consecutive channel bends requiring stabilization measures along their outer banks. Design criteria were principally based on the goals of reducing local velocities, shear stress and subsequent erosion at the outside bank of each bend, and on moving the thalweg away from the (existing) outside bank regions towards the centre of the channel. This paper reports on (i) the unique site conditions and environmental protection requirements, (ii) the results of the numerical simulation, and (iii) the design methodology.
\end{abstract}

Keywords: barb, submerged groyne, channel bend, field study, numerical model.

\section{Introduction}

Stream barbs (a type of submerged groyne) are low-profile linear rock structures, which are generally located as a series of two or more structures on the outside bank of meander bends, and which prevent the erosion of stream banks by redirecting high velocity flow away from the bank. The construction of stream barbs in Sawmill Creek, Ottawa, Canada will serve as a demonstration project for the use of barbs as a new bank stabilization technique that will contribute to 
the rehabilitation of urban creeks while reducing erosion threats to property and infrastructure. Stream barbs are a relatively low cost technique for bank protection, as compared to traditional revetment, due to reduced construction material requirements and maintenance costs. Moreover, as well as providing bank protection, these structures promote vegetated stream banks, maintain deep pool habitats through the development of scour holes at barb tips and increase bio-diversity for aquatic species $[1,2]$.

Stream barbs have been used by the United States Natural Resources Conservation Service (NRCS) in Oregon since the late 1980s [3] and by the Washington State Department of Transportation (WSDOT) [4] for river and stream bank protection along highways and river crossings and in some cases also to improve aquatic conditions, especially in shallow gravel bed streams. However, despite their relatively extensive use, documentation of long-term performance and specific design criteria are limited. The most authoritative guideline is provided by the United States Department of Agriculture (USDA) [3], which is recommended for meandering, alluvial river systems, and which was followed closely when establishing initial barb layouts for the present design at Sawmill Creek.

As a field test site, Sawmill Creek presents a unique opportunity to study the interesting flow field and sediment transport processes associated with a submerged structure. The submerged nature of these structures and the fact that they are typically placed in channel bends (where secondary flow dominates) creates a unique combination of vertical flow separation and overtopping (plunging) flow conditions, causing large and small scale three-dimensional (3D) eddies to form. Quantifying the influence of these 3-D turbulent eddies on the bed will improve predictions of sediment transport and as a result, will allow for better estimates of scour, bank erosion and overall channel morphology.

The chosen field test site also has the added complexity of having a clay bed and banks, which will allow further study of the erosional behaviour of cohesive soils, a topic which remains poorly understood. Clay bed channels are common in the Ottawa area and it is anticipated that successful implementation of stream barbs at this site will provide a good opportunity for promoting this method of bank protection at other sites in the municipality. The objective of this research is to use the Sawmill Creek test site as a case study for stream barb design and installation practices with the ultimate goal of developing design guidelines for routine employment of these structures to stabilize banks and improve aquatic habitat for semi-alluvial (clay) channels.

\subsection{Site information}

Sawmill Creek is located in the City of Ottawa, Canada, south of the Rideau Canal and drains north into the Rideau River. It has a total watershed area of $27.7 \mathrm{~km}^{2}$ and an approximate length of $10 \mathrm{~km}$ [5]. Sawmill Creek has a highly urbanized watershed that responds quickly to rainfall, experiencing large and rapid fluctuations in discharge and water depth following heavy rainfall events.

A $50 \mathrm{~m}$ section of Sawmill Creek (which receives approximately $90 \%$ of the contributing watershed area) is experiencing bank erosion and mass wasting at 
two particular bends, referred to here as bend 1 and bend 2 (Fig. 1). The proposed remedial work will provide measures for both bank stabilization and bank protection through the construction of a series of submerged stream barbs coupled with vegetative planting.
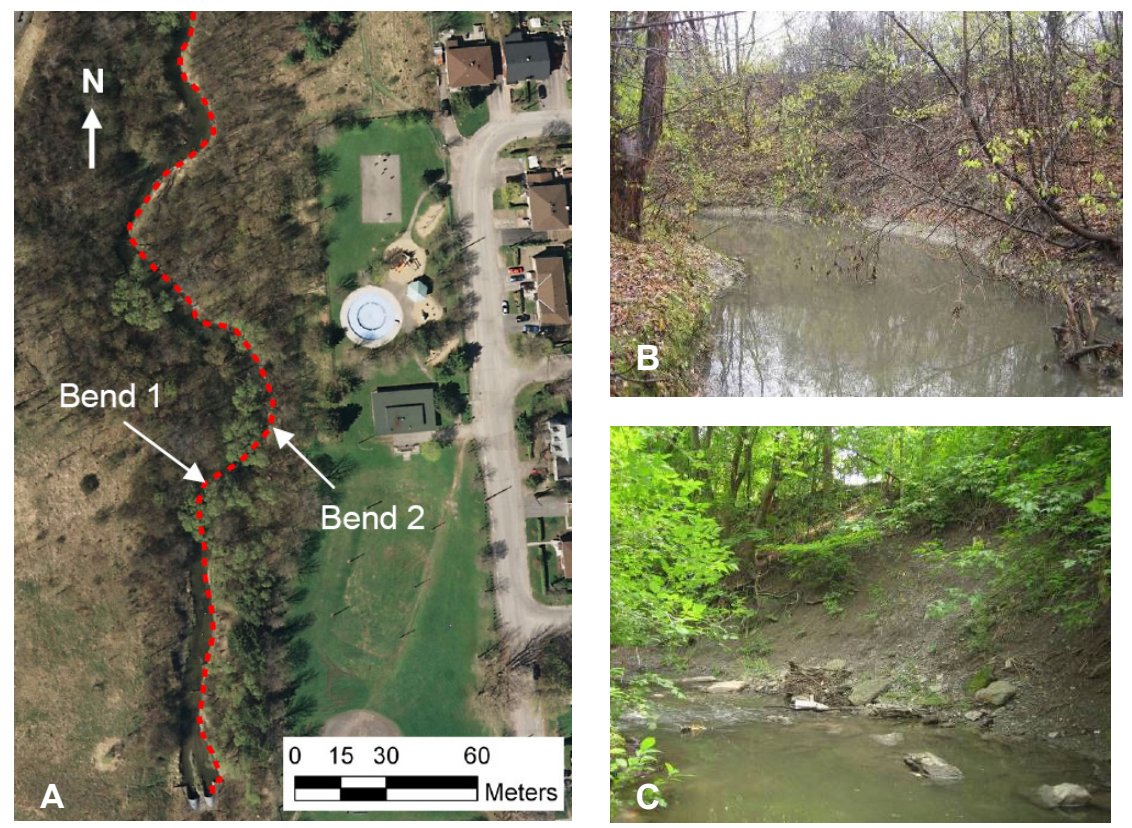

Figure 1: (A) Aerial photo of the Sawmill Creek study area; red dashed line indicates right bank and flow is from south to north. (B) Bend 1 looking upstream, and (C) outside bank of bend 2 looking downstream.

Sawmill Creek is a predominately clay bed channel, with a mix of coarse sand and gravel in the riffles. In the bend 2 section, a number of large boulders dominate and form a riffle, close to the apex of the bend (Fig. 1C). In typical river morphology, larger sediment sizes and an established riffle at the apex of the bend are unexpected. It is speculated that these boulders are the remnants of previous bank hardening measures, which over time fell from the steep side slope into the channel to create the riffle. (Pieces of concrete and asphalt found in the riffle area support this hypothesis).

Low flow and bankfull water depth and channel width at each bend apex are given in Table 1. Low flow and bankfull conditions were designated based on field observations and hydrological data from a gauging station located approximately $1.2 \mathrm{~km}$ downstream of the site. Hydrological data were obtained for the period of 2002-2007 (excluding 2003) and indicate that the average base (low) flow is approximately $0.20 \mathrm{~m}^{3} / \mathrm{s}$.

Based on an interpretation of available hydrological data and channel indicators surveyed at the site immediately following a bankfull event during 
July 2007, the current bankfull discharge at the gauge is estimated to be about $9.0 \mathrm{~m}^{3} / \mathrm{s}$. The associated water surface elevation for bankfull discharge is estimated to be $65.7 \mathrm{~m}$, based on field measurements from the July 2007 storm event where maximum discharge at the downstream gauging station was $8.86 \mathrm{~m}^{3} / \mathrm{s}$. For design purposes, a bankfull discharge of $9.0 \mathrm{~m}^{3} / \mathrm{s}$ at the site has been employed, which is considered conservative since the gauge is downstream of the site, wherein the contributing watershed at the site is $92 \%$ of the watershed at the gauge.

Table 1: $\quad$ Summary of flow conditions at the study site. ( $Q$ is discharge; $Z$ is water surface elevation; $y$ is water depth; $B$ is water surface width).

\begin{tabular}{cccccc}
\hline Location & Condition & $Q\left(\mathrm{~m}^{3} / \mathrm{s}\right)$ & $Z(\mathrm{~m})$ & $y(\mathrm{~m})$ & $B(\mathrm{~m})$ \\
\hline Bend 1 apex & Low flow & 0.20 & 65.0 & 0.70 & 5.0 \\
Bend 1 apex & Bankfull & 9.0 & 65.7 & 1.40 & 7.4 \\
Bend 2 apex & Low flow & 0.20 & 65.0 & 0.30 & 4.3 \\
Bend 2 apex & Bankfull & 9.0 & 65.7 & 1.00 & 7.7 \\
\hline
\end{tabular}

\section{Numerical model}

The 3-D numerical model used in this study was Sediment Simulation in Intakes with Multiblock option (SSIIM), Version 1.1. This model, which was developed at the Norwegian University of Science and Technology [6], uses a 3-D structured and non-orthogonal grid to simulate flow and sediment transport. The 3-D Reynolds-averaged Navier-Stokes equations are solved to calculate water flow, with the $k-\varepsilon$ turbulence model to resolve the Reynolds stresses. The SIMPLE method is used to solve the pressure term. The suspended sediment transport is calculated with the convection-diffusion equation and the volumetric bedload transport is calculated using van Rijn's bedload transport formula. (Other sediment transport formulas are available, but have not been tested in SSIIM). SSIIM has been successfully used to model flow and sediment transport in meandering self-forming channels [7]; 90 and $135^{\circ}$ bends [8, 9]; and overbank flow in a meandering channel [10].

Without detailed field measurements of the flow field and change in channel geometry over time, it is difficult to calibrate correctly the numerical model to simulate the current field conditions. Therefore, the modelling was used as a tool for testing different configurations of barb layouts and orientations. The modelling results represent a relative comparison of the change in bathymetry and patterns of velocity before and after the addition of stream barbs and, considering the criteria discussed in Section 3, an optimum design was achieved on this basis.

\subsection{Model development}

The numerical model (SSIIM version 1.1) uses a structured grid to define the model boundaries, channel geometry and computational domain. The entire 
length of the modelled reach is $167 \mathrm{~m}$, with the first bend approximately $83 \mathrm{~m}$ downstream of the model's upstream boundary and the second bend approximately $55 \mathrm{~m}$ upstream of the downstream boundary. To generate the grid, a digital elevation model was developed based on the interpolation of 500 topographical survey points, from 29 cross sections and additional top-of-bank and thalweg survey points. To generate the grid mesh for use in SSIIM, 228 cross sections, with 21 nodes per cross section, were digitized on the interpolated ground model and used to define the location of each grid node in the model. In the vertical direction, 10 grid points ( 9 cells) were defined from bed to water surface, with a higher resolution of points near the bed. The model grid is shown in Fig. 2A. The grid spacing in the two bend sections in the vicinity of the proposed barbs was also reduced to improve the resolution in these regions for better flow and sediment transport calculations, and to allow greater flexibility when testing various barb geometries and spacing (Fig. 2A).

The initial bathymetry is shown in Fig. 2B and represents the current bathymetry of the channel (i.e. before any numerical simulation), based on the interpolated ground model from the topographical survey data. The topographical survey was also used as a base map for the design plans.

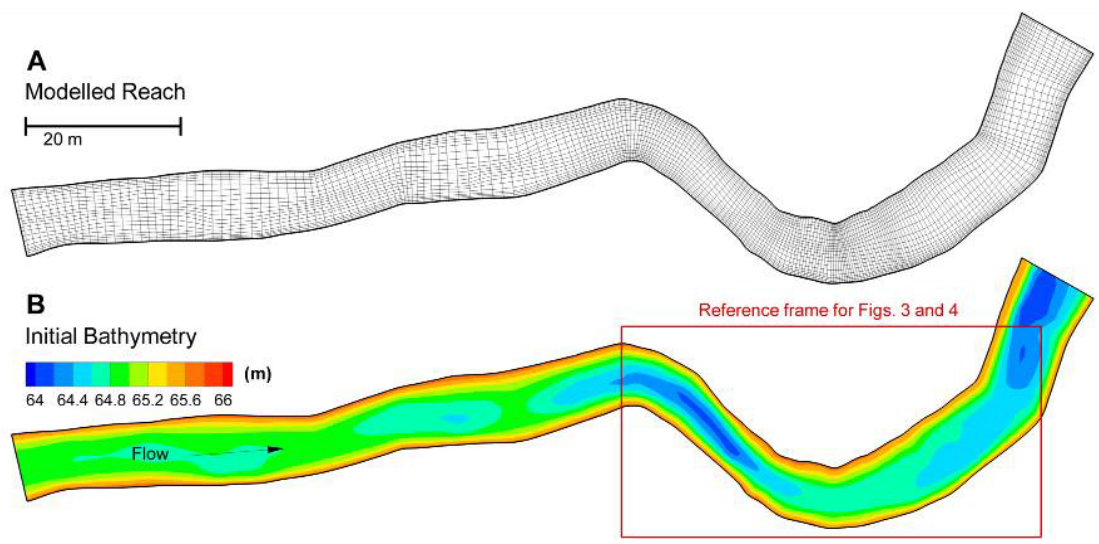

Figure 2: $\quad$ Modelled reach and initial bed elevations: (A) Mesh of modelled reach; (B) Initial bathymetry.

To calculate the water surface, SSIIM requires the following model input parameters: downstream water level, discharge and roughness. Downstream water surface elevation was set at $65.5 \mathrm{~m}$ in order to achieve a bankfull water depth of $65.7 \mathrm{~m}$ near the two channel bends; discharge was set at $9.0 \mathrm{~m}^{3} / \mathrm{s}$ (design bankfull discharge); roughness (which is defined in the model as equivalent to a diameter of particles on the bed) was set at $0.005 \mathrm{~m}$; and Shield's coefficient (used for defining critical shear stress for particle transport) at 0.055 . The most sensitive parameter to bed level changes was found to be the Shield's coefficient. Rather than estimate a Shield's coefficient based on the mean particle size from field samples, which would be difficult to define accurately due to the cohesive 
properties of the soil at the study location, this parameter was specified on the basis of establishing minimal sediment transport in the reference run (i.e. no barbs). Therefore, when the barb structures were added to the model, any change in flow and channel morphology would be considered due to barb layout, geometry and orientation alone.

The barb structures were modelled in SSIIM using a procedure described in [11], where cells defining the location of the barbs in the computational grid are blocked out. These cells are defined by fixed grid points with no slip conditions specified along the cell. This method of "out blocking" was successfully used in past numerical simulations to model submerged stream barbs in a laboratory channel bend, wherein a statistical comparison of the measured bed elevations from laboratory experiments [12] and predicted values from numerical simulation [9] gave a regression coefficient of determination $\left(\mathrm{r}^{2}\right)$ of 0.8 [9]. Details of the current numerical modelling results are presented in the next section.

\section{Stream barb design}

The primary objective of the hydraulic modelling was to test different configurations of barb layout, geometry and orientation on this particular reach of Sawmill Creek such that an optimum design could be achieved. The criteria for optimum barb design were:

- reduce flow velocity and shear stress along the outer bank of each bend;

- prevent erosion at the outer bank of each bend;

- shift thalweg to the center of the channel and make thalweg deeper (more stable);

- cause no morphological changes to the channel upstream or downstream of the two bends;

To satisfy these criteria, the modelling approach taken was to: (1) use the hydraulic model to establish base conditions of the channel (i.e. a stable reference simulation without barbs) and then; (2) test different configurations of barb layouts to ensure these criteria are met.

Using a combination of current guidelines [3] for the initial barb system layout and the results of intermediate numerical simulations for optimization, a final system layout was established. The layout was considered final when it successfully met the design criteria outlined above. Details of the final barb system layout (barb number, length, angle and spacing) are provided in Table 2. The final design incorporates the placement of seven barbs, three in the first bend and four in the second bend (Fig. 3).

Barb length is measured from the barb key at bankfull elevation to barb tip and barb alignment angle is the angle between the centerline of the barb and the tangent to the local stream-bank at bankfull elevation (Fig. 5). Barb spacing is the distance between the midpoint of consecutive barbs along one bend.

The results of previous laboratory experiments [12] and numerical modelling [9] found that barb alignment angle plays an important role in barb system performance. In these experiments, which considered 90 and $135^{\circ}$ channel bends, 
Table 2: Summary of barb details. Barbs are numbered in order in downstream direction (refer to Fig. 3).

\begin{tabular}{ccccc}
\hline Barb No. & Bank Location & Length $(m)$ & Angle $\left(^{\circ}\right)$ & Spacing $(m)$ \\
\hline 1 & Left & 2.6 & 35 & 8.1 \\
2 & Left & 2.6 & 35 & 7.0 \\
3 & Left & 2.6 & 35 & - \\
4 & Right & 2.9 & 35 & 6.3 \\
5 & Right & 2.8 & 30 & 9.1 \\
6 & Right & 3.4 & 30 & 11.5 \\
7 & Right & 3.3 & 25 & \\
\hline
\end{tabular}

optimum bank protection was achieved for a series of three barbs, each with an alignment angle of $30^{\circ}$.

Stream barb length in the first bend is less than in the second bend in order to accommodate the narrower channel width through this bend: USDA guidelines recommend that barb lengths should not exceed one-third of the cross section top width at bankfull flow. However, to ensure sufficient flow is captured by the shorter barb lengths, the angle of the three barbs in the first bend were specified as $35^{\circ}$ (i.e. greater than the recommended $30^{\circ}$ ). Erosion in bend 1 was more significant than bend 2 (Fig. 3), requiring greater deflection of high velocity flow away from the bank, and therefore greater barb angles.

Barb spacing varies according to bend curvature; the sharper the radius of curvature, the more closely spaced the barbs should be placed [3]. Observance of this guideline is reflected in the specified barb spacing of the final design (Table 2 and Figs. 3 and 4).

\subsection{Simulation results}

Numerical modelling results are presented in Figs. 3 and 4, for both the reference simulation, Case 1 (without barbs) and the final barb layout, Case 2. Figure 3 illustrates the bed level changes $(\Delta Z)$ and distribution of bed shear stress $(\tau)$ for each simulation case. A comparison of these plots reveals the effect that the barbs have on $\Delta \mathrm{Z}$ and on the distribution of $\tau$ : erosion at the outside bank of each bend has been prevented (A2 versus A1); and bed shear stress alongside the outer banks of each bend has been reduced (B2 versus B1). The bed shear stress in the centre of the channel has increased and become more concentrated in the centre for the case with barbs, suggesting that this barb arrangement would promote the development of a new, more stable thalweg in the channel centre through increased transport in this region.

Figure 4 shows the distribution of streamwise velocity (U) before and after the addition of barbs (A1 verses A2). As expected, the barbs cause a noticeable reduction in streamwise velocity along the outer bank, which corresponds with the observed reduction in bed shear stress in the same outer bank regions.

Figure 4 also shows the change in vertical velocity through the bend (B1 and B2). The presence of secondary flow, which is characteristic of flow in a bend, is best seen in the regions of high negative (blue) and positive (red) contours of 

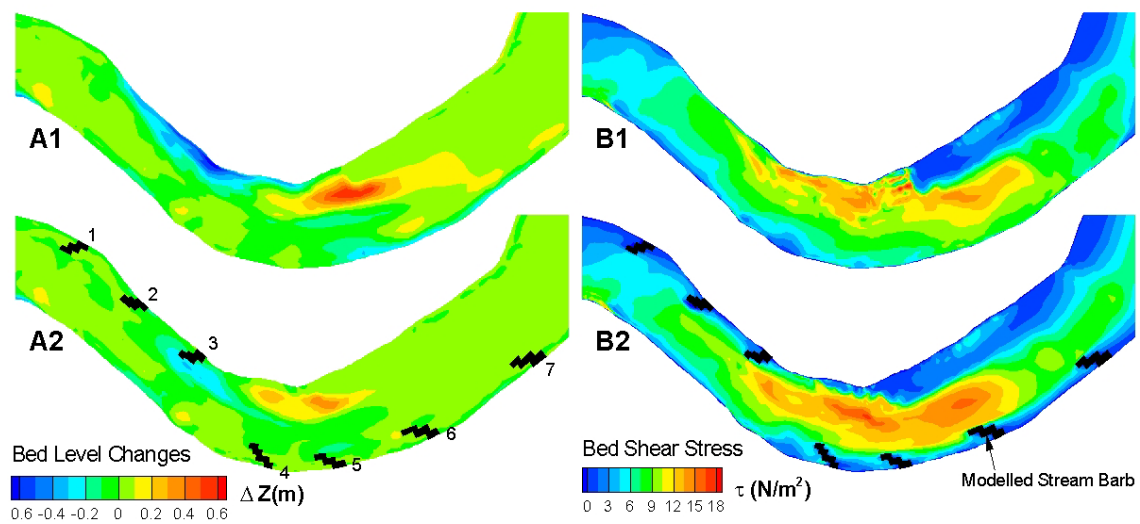

Figure 3: $\quad$ Contours of bed level changes $(\Delta \mathrm{Z})$ and bed shear stress $(\tau)$ before $(\mathrm{A} 1, \mathrm{~B} 1)$ and after (A2, B2) the addition of barbs. Flow is from left to right. Barb numbers are labelled in A2.
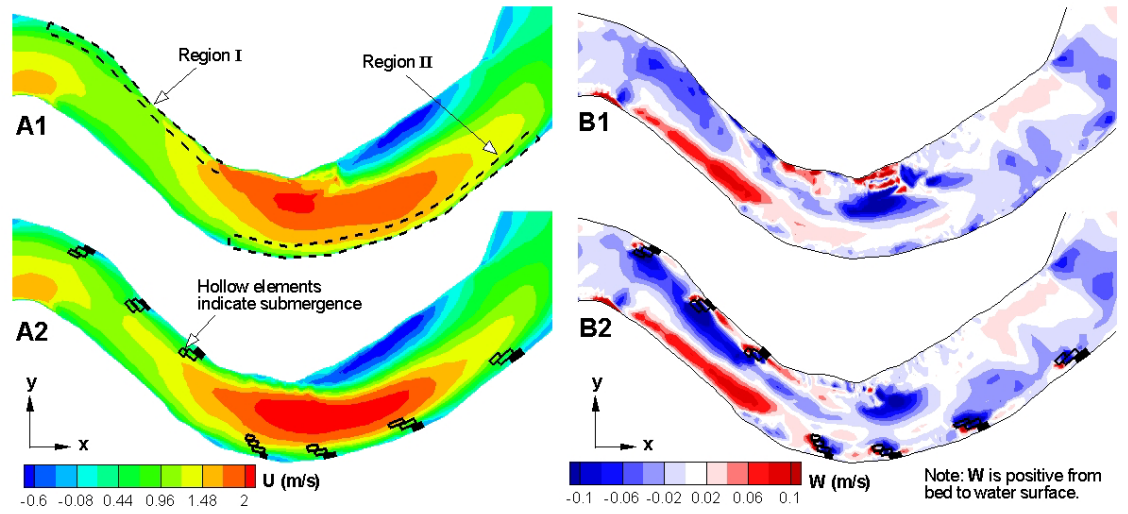

Figure 4: Contours of streamwise (U) and vertical (W) velocity at $60 \%$ of the flow depth before (A1, B1) and after (A2, B2) the addition of barbs. Flow is from left to right.

vertical velocity at the inside and outside regions of bend 1, respectively (Fig. 4 B1). Secondary flow is less pronounced in the second bend, most likely due to the shallowing of the local topography (due to the spurious riffle), which has disrupted this flow pattern. Despite this, the addition of stream barbs has clearly lead to a more complex, 3-D velocity pattern in the near vicinity of each structure. Extreme positive and negative values of vertical velocity, upstream and downstream of each barb structure respectively, illustrate the plunging action of the flow as it passes over the submerged structure. This resultant 3-D flow pattern is essential to the effectiveness of these structures in disrupting and redirecting the erosion-causing outer bank velocities (i.e. high streamwise and 
secondary flow velocities) and promoting the development of scour at the barb tips.

A quantitative comparison between each simulation case can be made by calculating the mean values of $\Delta \mathrm{Z}, \tau$ and $\mathrm{U}$ in the vicinity of each series of stream barbs along each bend. Two regions, which represent the near bank flow field for each series of barbs along the left (Region I) and right (Region II) banks have been defined and are shown in Fig. 4A1. The calculated mean values of each variable $(\Delta Z, \tau$ and $U)$ for each case (Case $1=$ no barbs; Case $2=$ with barbs) and region (I or II) are given in Table 3 . These results confirm the substantial reduction in erosion, $\Delta \mathrm{Z}$ (68 and 98\%), bed shear stress, $\tau$ (56 and $59 \%$ ) and streamwise velocity, $U$ (51 and 51\%) achieved by the addition of the proposed barb layout for Regions I and II respectively.

Table 3: $\quad$ Mean values and percentage change for near bank Regions I and II. Case 1 and 2 represent modelling results for before and after the addition of barbs respectively. $\Delta \mathrm{Z}$ is bed level change, $\tau$ is bed shear stress and $\mathrm{U}$ is streamwise velocity at $60 \%$ of the flow depth. (Region I and II boundaries are shown in Fig. 4A1).

\begin{tabular}{|c|c|c|c|c|c|c|c|c|c|}
\hline \multirow{3}{*}{ Region } & \multicolumn{3}{|c|}{$\Delta \mathrm{Z}(\mathrm{m})$} & \multicolumn{3}{|c|}{$\tau\left(\mathrm{N} / \mathrm{m}^{2}\right)$} & \multicolumn{3}{|c|}{$U(\mathrm{~m} / \mathrm{s})$} \\
\hline & \multicolumn{2}{|c|}{ Case } & \multirow{2}{*}{$\begin{array}{c}\text { Change } \\
(\%)\end{array}$} & \multicolumn{2}{|c|}{ Case } & \multirow{2}{*}{$\begin{array}{c}\text { Change } \\
(\%)\end{array}$} & \multicolumn{2}{|c|}{ Case } & \multirow{2}{*}{$\begin{array}{c}\text { Change } \\
(\%)\end{array}$} \\
\hline & 1 & 2 & & 1 & 2 & & 1 & 2 & \\
\hline I & -0.222 & -0.068 & -68 & 6.575 & 2.877 & -56 & 0.990 & 0.490 & -51 \\
\hline II & -0.083 & -0.002 & -98 & 5.676 & 2.302 & -59 & 1.028 & 0.501 & -51 \\
\hline
\end{tabular}

The simulation results show that all but one criterion have been satisfied; the thalweg did not get noticeably deeper (Fig. 3). While the barbs have reduced outer bank erosion, there is no obvious increase in scour at the barb tips (except for the case of barb 3), which would be required for the formation of a new, more stable and centered thalweg. This is likely due to the model parameters (i.e. Shield's criterion) that were specified purposely to inhibit sediment transport in the reference run scenario, thereby potentially under-predicting the sediment transport in the vicinity of the structure. Without detailed field measurements for calibration, morphological changes are difficult to quantify substantively. Therefore, this criterion (thalweg shift) was not considered critical during the model testing as it is largely dependent on the specified sediment transport parameters, which could not be modelled exactly.

\subsection{Design and installation plan}

Stream barbs reduce bank toe scour and velocity induced erosion; however, these structures do not address bank failure due to soil instability and drawdown/saturation [3]. Therefore, as part of the overall strategy for stream restoration and the prevention of stream bank erosion at Sawmill Creek, additional work is proposed, including: stream cleanup; vegetative planting; and site monitoring. The plan is to incorporate vegetative planting and other 
bioengineering practices during the construction phase to address these additional mechanisms of bank failure. Moreover, vegetation provides additional roughness to dissipate energy along the stream bank and enhances wildlife habitat and water quality.

The design reach will be monitored for flow hydraulics and fish utilization. Specifically, the 3-D flow field, bed and bank morphology, fish habitat, and fish and benthic invertebrate populations will be measured throughout the design reach, for both pre- and post-installation conditions, for a period of three years.

Figure 5 illustrates the design details of a single barb structure in plan, elevation and cross-section views. Barbs will be constructed out of large rock riprap, between 500 and $600 \mathrm{~mm}$ in diameter, with additional smaller riprap $\left(\mathrm{d}_{50}\right.$ $\sim 230 \mathrm{~mm})$ along the bank side slope (50\% above/below bankfull) upstream of each barb to provide additional protection in this area.
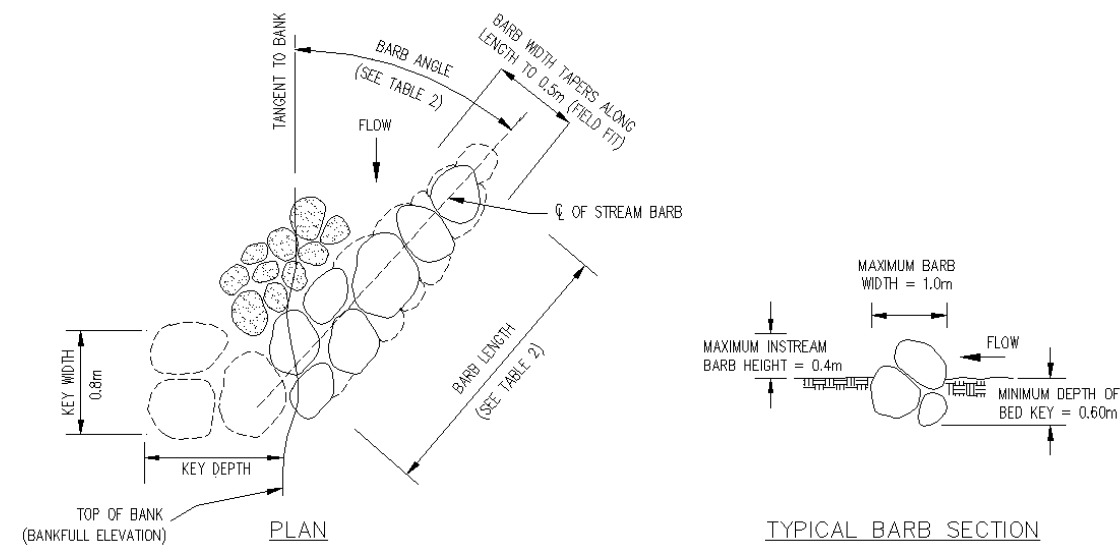

TYPICAL BARB SECTION

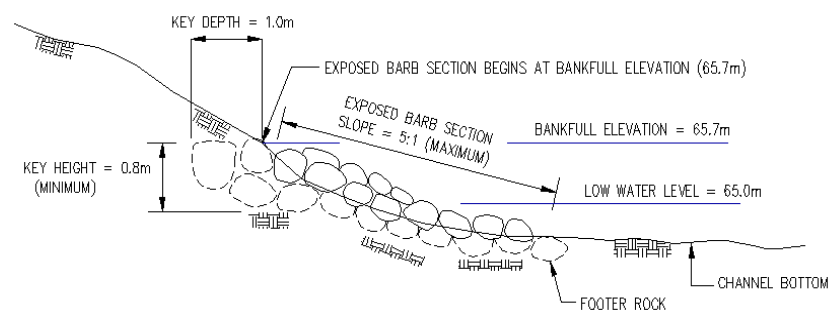

ELEVATION

Figure 5: Barb design details: Plan (top left); Section (top right); and Elevation (bottom) views.

According to the USDA Design Guidelines [3] and based on field observations, there are four common modes of barb structure failure. In the past, barbs were installed throughout the United States with limited or no guidance and as a result, several failures could have been avoided [3]. These failure modes are: (1) flanking of the barb, which occurs when the horizontal angle is too large, 
the key length too short, and/or the spacing between barbs is too large; (2) the structure is undermined downstream, which occurs when the footer rock depth is too shallow; (3) Erosion occurs between barbs, which happens when the barb spacing is too great or the horizontal angle is too large, causing greater capture of the stream flow and promoting an area of recirculating flow behind the structure; (4) rock displacement, which occurs as a result to poor construction techniques leading to weir section rocks that are not locked together.

To ensure that the proposed barb design for Sawmill Creek is not susceptible to failure, the following steps have been incorporated during the design process:

- The key length for each barb has been specified as greater than one-third the barb length which, according to USDA guidelines [3] is a conservative value.

- A threshold stability analysis has been carried out to test the (1) sliding and (2) overturning or moment stability of the riprap elements. The numerical modelling results were used to identify the maximum anticipated local velocities. This analysis represents a conservative scenario, as lateral anchoring and shielding of surrounding boulders provide for an additional factor of safety.

- The riprap at the base of each barb should be placed a minimum of $0.6 \mathrm{~m}$ into the bed. This is referred to as the bed key and is necessary to prevent scour in the vicinity of the structure from causing the rock to fall into the scour hole.

\section{Conclusions}

The 3-D numerical model was capable of reproducing the expected distribution of secondary flow in a channel bend, the unique 3-D flow field in the vicinity of a series of stream barbs and the associated patterns of soil erosion and deposition. The numerical modelling was also demonstrated to be a useful tool for optimizing barb design for stream bank protection at the proposed field test site. Details of the numerical modelling results, final barb design and rationale behind the design process have been presented.

A comprehensive measurement campaign is planned for Spring 2009, wherein detailed velocity measurements through the two bends will be used for improved calibration of the numerical model base-case scenario. Installation of the stream barbs is tentatively scheduled during a period of dry weather and low flow conditions in August 2009.

\section{Acknowledgements}

The authors would like to acknowledge Darlene Conway at the City of Ottawa Department of Planning, Transit and the Environment for her valuable comments and leadership throughout the design and implementation phase of this ongoing research. Hydrological data and geographical information were obtained from the City of Ottawa Water Environment Protection Program and the Mapping and Surveying Department. This work was supported in part by grants from the 
Natural Sciences and Engineering Research Council of Canada and the Canadian Federation of Municipalities' Green Municipal Fund.

\section{References}

[1] Shields, F.D., Knight, S.S. \& Cooper, C. M. Addition of spurs to stone toe protection for warmwater fish habitat rehabilitation. J. American Water Res. Ass., 34, pp. 1427-1436, 1998.

[2] Engelhardtm C., Kruger, A., Sukhodolov A. A study of phytoplankton spatial distributions, flow structure and characteristics of mixing in a river reach with groynes. J. of Plankton Res., 26(11), pp. 1351-1366, 2004.

[3] Technical Note 23: Design of Stream Barbs, U.S. Department of Agriculture (USDA), Natural Resources Conservation Service, Portland Oregon, 2005.

[4] Papanicolaou, A.N.T., Kjos, L.J. and Fox, J.F. Investigation of Flow and Local Scour Characteristics around a Partially Submerged Permeable WSDOT Barb. Washington State Department of Transportation, Report No. WA-RD 581.1, 2004.

[5] Parish Geomorphic, Sawmill Creek Monitoring: Final Report. January, 2005.

[6] Olsen, N.R.B. A Three-dimensional Numerical Model for Simulation of Sediment Movements in Water Intakes with Multiblock Option: User's Manual. Department of Hydraulic and Environmental Engineering, Norwegian University of Science and Technology, Trondheim, Norway, 2004.

[7] Olsen, N.R.B. Three-dimensional CFD modelling of self-forming meandering channel. J. of Hydraulic Eng., 129(5), pp. 366-372, 2003.

[8] Ruther, N. and Olsen, N.B.R. Three-dimensional modelling of sediment transport in a narrow $90^{\circ}$ channel bend. J. of Hydraulic Eng. 131(10), pp. 917-920, 2005.

[9] Minor, B., Rennie, C.D. and Townsend, R.D. "Barbs" for river bend bank protection: application of a three-dimensional numerical model. Can. J. of Civil Eng. 34, pp. 1087-1095.

[10] Wormleaton, P.R. and Ewunetu, M. Three-dimensional k-e numerical modeling of overbank flow in a mobile bed meandering channel with floodplains of different depth, roughness and planform. J. of Hydraulic Res. 44(1), pp. 18-32, 2006.

[11] Olsen, N.R.B. A Three-dimensional Numerical Model for Simulation of Sediment Movements in Water Intakes with Multiblock Option: User's Manual, Department of Hydraulic and Environmental Engineering, Norwegian University of Science and Technology, 2005.

[12] Matsuura, T. and Townsend, R. Stream-barb installations for narrow channel bends - a laboratory study. Can. J. of Civil Eng., 31, pp. 478-486, 2004. 